Vol 11, Issue 12, 2018

\title{
KNOWLEDGE OF THE DISEASE AMONG TYPE 2 DIABETES PATIENTS IN A TERTIARY CARE HOSPITAL IN MUMBAI, INDIA
}

\author{
VIMAL PAHUJA ${ }^{1}$, GENEVIE FERNANDES ${ }^{2}$, NILESH CHATTERJEE ${ }^{3 *}$ \\ ${ }^{1}$ Consultant Metabolic Physician and Program Supervisor, Obesity and Diabetes Center of Excellence, Dr. L.H. Hiranandani Hospital, \\ Mumbai, Maharashtra, India, ${ }^{2}$ Usher Institute of Population Health Sciences and Informatics, University of Edinburgh, Edinburgh, \\ Scotland, ${ }^{3}$ Behavioral Science Consultant, Kalyani Media Group, Chembur, Mumbai, Maharashtra, India. \\ Email: nileshchatterjee100@gmail.com
}

Received: 05 July 2018, Revised and Accepted: 30 July 2018

\section{ABSTRACT}

Objective: An estimated 72 million in India live with diabetes; the country faces an impending health-care crisis with prevalence and complications of diabetes forecasted to multiply in the next decade. Improving patients' knowledge about diabetes to manage the disease better is an urgent and important public health goal.

Methods: Knowledge about diabetes, its complications, and management was surveyed using a structured questionnaire among 167 Type 2 diabetes patients attending a tertiary care hospital in Mumbai, India.

Results: None of the participants had ever received any formal diabetes self-management education previously. Respondents' mean and median correct knowledge scores were 20 of 32 test items. Although majority answered statements about blood sugar levels and complications, there was lack of knowledge about the causes and management of diabetes. Around $82 \%$ stated that medication was more important than dietary intake and physical activity in managing diabetes. A multiple regression model showed that postgraduate or graduate level education, not being married, having two or less children, and visiting a doctor 1-3 times a year (as compared to more than three visits) was independently associated with higher diabetes knowledge scores $(* p<0.05)$ in this sample.

Conclusion: An information disparity exists between patients who have higher levels of education versus those with lesser education. Future research will have to examine the mechanisms by which higher education contributes to better knowledge, and facilitate the design of diabetes education programs that bridge information gaps and improve required competencies in patients to better manage their condition.

Keywords: Diabetes mellitus, Diabetes knowledge, Diabetes education, Urban, India.

(C) 2018 The Authors. Published by Innovare Academic Sciences Pvt Ltd. This is an open access article under the CC BY license (http://creativecommons. org/licenses/by/4. 0/) DOI: http://dx.doi.org/10.22159/ajpcr.2018.v11i12.28126

\section{INTRODUCTION}

With an estimated 72 million affected, India has the second highest number of people living with diabetes in the world; second, only to China with 114 million [1]. The prevalence of diabetes in India is expected to rise to 366 million by 2030 [2]. Diabetes is also the seventh most common cause of death in India [3]. A recent study conducted in 15 of the 29 Indian states estimated diabetes prevalence at 7.3\%, varying from $4.3 \%$ in Bihar to $10 \%$ in Punjab, and a higher prevalence in urban compared to rural areas [4].

Diabetes, if not well controlled, leads to a higher risk of blindness due to retinopathy, kidney disease, cardiovascular disease, lower-extremity amputations, or pregnancy complications [5]. The global cost of diabetes is set to almost double to US $\$ 2.5$ trillion by 2030 , and even if countries meet internationally set diabetes prevention and control targets, the global economic burden from the disease will still increase by $88 \%$ [6]. Especially in low- and middle-income countries, where the majority of health-care costs are paid out of pocket, the costs of managing diabetes and treating its associated complications place a huge economic and emotional burden on the patient and their families [7].

In 2010, diabetes costs India around US $\$ 31.9$ billion [8]. Several studies in India have found that varying shares of household income are allocated to pay for diabetes care, especially hurting lower income households the most. A study of seven Indian states reported an annual median expenditure of INR 10,000 (US\$149) for diabetesrelated care in urban areas and INR 6260 (US\$93) in rural parts of the country. Majority of the patients (89\%) used their household income to fund the monitoring and treatment of their diabetes. Lower income groups spent the highest proportion of their income on diabetes costs (urban poor 34\% and rural poor 27\%) [9]. Diabetes patients without complications were found to have an $18 \%$ lower mean annual cost for outpatient care compared to those with three or more complications who spent $48 \%$ higher [10]. The prevailing epidemiological situation makes it imperative to understand how to prevent complications and improve management of diabetes in the country.

Correct knowledge about diabetes has been found to improve selfmanagement of the disease [11,12], prevent complications [13], and lead to better outcomes [14,15]. Studies have found that patients who do not receive formal diabetes self-management education (DSME) have knowledge gaps; they tend not to receive recommended preventive services and are more likely to develop complications than those who have received DSME [16,17]. While knowledge alone may not be sufficient in motivating behavior change for diabetes prevention and management, it remains a necessary step in helping patients accept their diagnosis and take an active role in self-care and management $[12,18]$

Previous studies have measured diabetes-related knowledge among general populations in India [19-21]; however, few have examined the knowledge levels of patients with diabetes in health-care facilities in urban cities $[22,23]$. This study aims to fill this gap in the literature by assessing the knowledge about diabetes, its complications, and management among type 2 diabetes patients attending a private 
tertiary care hospital in an urban area in India. Findings will also provide insights into the design and development of a hospital-based DSME program.

\section{METHODS}

\section{Study setting}

This cross-sectional study was conducted with inpatients at a private tertiary care hospital with 240 beds, located in central Mumbai. Although Mumbai is one of the wealthiest urban areas in India [24], $60 \%$ of its population of 12 million live in overcrowded slums [25], highlighting inequalities in income, and access to housing, education, water, and sanitation [26]. Public health services in Mumbai are offered at the primary, secondary, and tertiary level through 168 health posts, 162 dispensaries, five maternity homes along with 16 municipal general hospitals, 26 specialty hospitals, and four major teaching hospitals of the municipal corporation. Although these public hospitals provide low-cost services to patients, they are understaffed, overburdened, and often perceived as unable to offer quality health care. Therefore, many people prefer private health care, and private hospitals outnumber those run by the government [27].

\section{Sample}

A total of 167 in patients with a prior diagnosis of diabetes were purposively sampled from among a population of adults admitted to the inpatient wards of the tertiary hospital. Two trained interviewers, a junior physician and a diabetes nurse, fluent in English and Hindi, conducted interviews independently. Interviewers would request the floor nurse in charge to identify admitted patients with existing diagnosis of diabetes. If the patient had no procedures planned for the day, then interviewers approached patients at their respective bedsides; explained the study and requested participation after reading a printed consent form verbatim in English or Hindi depending on the language preferred by the patient. This consent form described the aims and implications of the study, interview procedure, confidentiality, and voluntary nature of participation. Patients were assured that they were free to withdraw from the research at any time and this would not affect any aspect of their care. Patients who were not diabetic and diabetic patients suffering from a severe ailment or in post-surgical state were not included in this study.

\section{Data collection}

Interviews were conducted only after gaining patient consent. Patients who agreed to participate were interviewed at the bedside in the ward after adequate privacy was ensured. Data collection was conducted in the afternoon between $2 \mathrm{pm}$ and $5 \mathrm{pm}$ with 167 respondents in a 5-week period. The questionnaire used in this study consisted of four sections: (i) Sociodemographic details, (ii) health profile including complications, (iii) diabetes control practices, and (iv) knowledge statements covering the disease. The knowledge assessment component of this questionnaire was adapted from the diabetes knowledge questionnaire developed in the Starr County Diabetes Education Study [28]. Before the actual survey, the questionnaire was pretested with a representative sample of six respondents in the same hospital. Each item in the knowledge test was checked for wording comprehension, and cognitive and perceptual problems. The final knowledge test had 32 statements with true/ false options; and test items could be classified into five categories: (i) Knowledge about the disease (eight statements), (ii) causes (3), (iii) consequences/complications (6), (iv) management (11), and (v) lifestyle - diet and activity (four statements).

\section{Data analysis}

Data were entered into MS-Excel 2007 and then analyzed using the SPSS software version 16.0. First, descriptive frequencies were generated for all variables. A total knowledge score variable was computed for each case by assigning 0 to incorrect and 1 to correct answers and then adding the responses to each knowledge statement. Thus, the lowest possible score was 0 and highest was 32 . Bivariate analysis was conducted wherein nominal and continuous independent variables were tested with the knowledge score as dependent variable. Finally, independent variables statistically significant at ${ }^{*} \mathrm{p}<0.05$ level in the bivariate analysis were included in a multiple regression model with knowledge score as the dependent variable. The study was approved by the Ethics Committee of Dr. L.H. Hiranandani Hospital, Mumbai.

\section{RESULTS}

\section{Sociodemographic profile}

Of 167 patients interviewed for this study, two-thirds had been diagnosed with diabetes more than 10 years ago, with mean and median of 14.6 and 13 years, respectively. About $63 \%$ aged between 55 and 74 years; $55 \%$ were female; $80 \%$ were married; and $60 \%$ had two or less than two children. Slightly more than two of five $(44 \%)$ respondents were graduates or postgraduates. Only half of the respondents $(50 \%)$ had health insurance, mainly an individual plan with out-of-pocket annual premium payments.

\section{Media use}

About $93 \%$ watched television and $82 \%$ read the newspaper every day. However, $36 \%$ reported never using a mobile phone, and a vast majority had never used email (91\%), Facebook (87\%), or YouTube (92\%). While most respondents did not use internet-based applications, around 23\% reported using WhatsApp, a mobile-phone based messaging application.

\section{Health profile}

Nearly three of five $(60 \%)$ had a body mass index (BMI) above $25 \mathrm{~kg} / \mathrm{m}^{2}$ considered obese for the Indian population; another $20 \%$ was overweight with a BMI ranging from 23 to $24.9 \mathrm{~kg} / \mathrm{m} 2$. Although more than two-thirds $(71 \%)$ reported having high blood pressure, almost $96 \%$ self-reported as non-smokers.

Around a third of the respondents had experienced reactions for low and high blood sugar in the month before the survey, nearly $10 \%$ reported one or more hospitalizations for hypoglycemia or hyperglycemia in year before the interview. About 30\% had been diagnosed with cardiovascular disease; $19 \%$ had peripheral neuropathy; $17 \%$ had autonomic neuropathy; $8 \%$ reported kidney disease; $5 \%$ were affected by retinopathy; and $1 \%$ had undergone foot amputation.

A "complication score" computed by adding respondent's affirmative response (Yes $=1 ; \mathrm{No}=0)$ to diabetes-related consequences including cardiovascular disease, peripheral neuropathy, autonomic neuropathy, retinopathy, and kidney disease showed a mean complication score of 0.80 , a median of 0 , and minimum and maximum score of 0 and 5 , respectively. A "comorbidities score" was computed by adding respondent's affirmative response (Yes $=1 ; \mathrm{No}=0)$ to two comorbidities associated with diabetes, i.e., high blood pressure and high cholesterol. The mean comorbidities score was 0.84 and median was 1 .

\section{Diabetes-related care seeking and quality of life}

Seven in ten respondents reported visiting a diabetes specialist (76\%) while $24 \%$ saw a general practitioner. About $57 \%$ visited their doctor 1-3 times a year. Around $40 \%$ had not tested blood sugar levels in 4 weeks preceding the interview. Two of five $(39 \%)$ respondents felt that diabetes had kept them from doing normal life activities in the past year, and 36\% said that diabetes had made their life difficult. Almost $96 \%$ of the respondents had not received any formal DSME.

\section{Diabetes-related knowledge}

The mean and median knowledge scores were 20 each, with the lowest and highest scores of 0 and 30 of a highest score possible of 32 Table 3. Knowledge about blood sugar levels and complications was high with at least four of five respondents providing correct answers to some of these statements: Amount of blood sugar increases if diabetes is left untreated (94\%); shaking and sweating are signs of high blood sugar (89\%); frequent urination and thirst are signs of low blood sugar (89\%); fasting blood sugar of 210 is considered high (86\%); diabetes may cause poor circulation (86\%); cuts and abrasions heal slowly among diabetics (83\%); diabetes can damage the kidney (81\%); and diabetes can cause loss of feeling in hands, fingers, and feet $(79 \%)$. 
However, only half (51.5\%) said that infection is likely to cause an increase in blood sugar levels.

While $87 \%$ of the respondents said that food preparation methods were as important as the food consumed and $70 \%$ said that regular exercise will not increase the need for insulin or other medication, nearly $82 \%$ thought that medication was more important than diet or physical activity in the control of diabetes. Similarly, although $80 \%$ said that regular checkups with a doctor help to spot early signs of complications, $62 \%$ were unaware of the need to lie down in case of a low blood glucose reaction.

Knowledge about prevention and management of complications was mixed - $<60 \%$ correctly answered statements about diabetes testing mechanisms, cleaning of wounds, cutting of toenails, and wearing tight elastic hose or socks. Almost $60 \%$ of respondents did not know that there are two types of diabetes; $40 \%$ said that diabetes can be cured; and $30 \%$ were unaware that their children may have a higher chance of developing diabetes.

A bivariate analysis with the knowledge score as the dependent variable and various independent variables in Tables 1 and 2 revealed that knowledge was significantly higher in respondents who were not married (21.88) as compared with those who were married (19.59) $\left({ }^{*} \mathrm{p}<0.05\right)$; respondents with two or less children $(21.41)$ versus those with three or more children (18.22) $(* \mathrm{p}<0.05)$. Similarly, the knowledge score was higher in graduates or postgraduates (21.66) as compared to those with $<9^{\text {th }}$ grade schooling $(17.73)(* \mathrm{p}<0.05)$. Respondents, who consulted a specialist (20.55) and visited this doctor 1-3 times a year (20.96), had higher knowledge scores compared with those who consulted a general practitioner (18.13) and reported more than three visits to the doctor $(18.97)\left({ }^{*} \mathrm{p}<0.05\right)$. Those with two diabetesrelated hospitalizations had a lower knowledge score (11) as compared to those with zero or one hospitalization episode $(20.04,20.87)$ $\left({ }^{*} \mathrm{p}<0.05\right)$. Respondents who said that diabetes had never stopped them from doing normal life activities had a higher knowledge score (21.19) than those felt otherwise $(18.11)\left({ }^{*} \mathrm{p}<0.05\right)$. Similarly, respondents who disagreed with the statement - "Diabetes makes life difficult" had higher knowledge scores (20.78) versus those who agreed (18.58) $\left(^{*} p<0.05\right)$.

A multiple regression was run with the dependent variable of knowledge score and the following independent variables: Respondents' marital status, number of children, education level, type of doctor consulted, number of annual visits to the doctor, number of hospitalizations, and responses to the statements "Diabetes affects normal activities in life" and "diabetes makes life difficult" (Table 4). The multiple regression model statistically significantly predicted knowledge score, $\mathrm{F}=5.611,{ }^{* *} \mathrm{p}<0.001$, although adjusted $\mathrm{R}^{2}$ was only 0.20 . Knowledge scores were found to be significantly higher in respondents who had graduate or postgraduate level education, were not married, had two or fewer children, and had one to three annual visits to the doctor for diabetes care $\left({ }^{*} \mathrm{p}<0.05\right)$.

\section{DISCUSSION}

This study sought to determine knowledge levels about diabetes, its causes and complications, and management among Type 2 diabetes patients attending a tertiary care hospital in the urban area of Mumbai, India. Both mean and median diabetes knowledge scores were 20 of 32 test items (or 62\%). Postgraduate or graduate level education, not being married, having two or less children, and consulting a doctor 1-3 times a year (as compared to more than three visits) were significantly associated with higher diabetes knowledge scores.

While the majority answered the items on blood sugar and complications correctly, there was a lack of correct knowledge about causes and management of the disease; most respondents also stated that medication was more important than diet and physical activity. Several studies have reported similar findings of knowledge deficit in these areas [17,29-32].
Table 1: Sociodemographic variables with the mean knowledge score $(n=167)$

\begin{tabular}{|c|c|c|c|}
\hline Characteristics & n (\%) & Mean knowledge score & p value \\
\hline \multicolumn{4}{|c|}{ Age in years (median=65; mean=64.26; SD=11.13; $\operatorname{Min}=34 ; \mathrm{Max}=86$ ) } \\
\hline$\leq 54$ & $30(18)$ & 20.07 & \multirow[t]{4}{*}{0.897} \\
\hline $55-64$ & $53(32)$ & 19.68 & \\
\hline $65-74$ & $53(32)$ & 19.85 & \\
\hline$\geq 75$ & $31(18)$ & 20.68 & \\
\hline \multicolumn{4}{|l|}{ Sex } \\
\hline Female & $76(45)$ & 19.80 & \multirow[t]{2}{*}{0.712} \\
\hline Male & $91(55)$ & 20.14 & \\
\hline \multicolumn{4}{|c|}{ Marital status $(n=164)$} \\
\hline Married & $132(80)$ & 19.59 & \multirow[t]{2}{*}{0.040} \\
\hline Others & $32(20)$ & 21.88 & \\
\hline \multirow{2}{*}{\multicolumn{4}{|c|}{$\begin{array}{l}\text { Number of children (median }=2 ; \text { mean }=2.61 ; S D=1.37 ; \operatorname{Min}=0 \text {; } \\
M a x=8 \text { ) }\end{array}$}} \\
\hline & & & \\
\hline$\leq 2$ children & $98(60)$ & 21.41 & \multirow[t]{2}{*}{0.001} \\
\hline$\geq 3$ children & $65(40)$ & 18.22 & \\
\hline \multicolumn{4}{|c|}{ Years of education $(n=159)$} \\
\hline$\leq 9^{\text {th }}$ grade & $30(19)$ & 17.73 & \multirow[t]{3}{*}{0.006} \\
\hline $\begin{array}{l}10-12 \text { and some } \\
\text { college }\end{array}$ & $59(37)$ & 19.66 & \\
\hline $\begin{array}{l}\text { Graduates/ } \\
\text { postgraduates }\end{array}$ & $70(44)$ & 21.66 & \\
\hline \multicolumn{4}{|c|}{ Personal monthly income (In Indian rupees) $(n=136)$} \\
\hline$<$ Rs. 25,000 & $132(97)$ & 20.80 & \multirow[t]{4}{*}{0.284} \\
\hline $\begin{array}{l}\text { Rs. } 25,000-\text { Rs. } \\
49,000\end{array}$ & $2(1)$ & 22 & \\
\hline $\begin{array}{l}\text { Rs. 50,000-Rs. } \\
99,000\end{array}$ & $1(1)$ & 11 & \\
\hline$\geq$ Rs. 100,000 & $1(1)$ & 15 & \\
\hline \multicolumn{4}{|c|}{ Health insurance status $(\mathrm{n}=167)$} \\
\hline Yes & $84(50)$ & 20.17 & \multirow[t]{2}{*}{0.695} \\
\hline No & $83(50)$ & 19.81 & \\
\hline \multicolumn{4}{|c|}{ Frequency of media use } \\
\hline \multicolumn{4}{|c|}{ Newspaper $(n=163)$} \\
\hline Never & $26(16)$ & 20.77 & \multirow[t]{3}{*}{0.257} \\
\hline $\begin{array}{l}2-3 \text { times a } \\
\text { week }\end{array}$ & $3(2)$ & 25 & \\
\hline Every day & $134(82)$ & 19.90 & \\
\hline Television $(n=163)$ & & & \\
\hline Never & $12(7)$ & 17.08 & 0.055 \\
\hline Every day & $151(93)$ & 20.37 & \\
\hline Radio $(n=160)$ & & & \\
\hline Never & $123(76)$ & 20.13 & 0.160 \\
\hline Once a month & $2(1)$ & 14 & \\
\hline Once a week & $3(2)$ & 14.67 & \\
\hline Every day & $32(20)$ & 20.56 & \\
\hline Mobile phone for $\mathrm{c}$ & ls $(n=163)$ & & \\
\hline Never & $58(36)$ & 18.83 & 0.060 \\
\hline $\begin{array}{l}2-3 \text { times a } \\
\text { week }\end{array}$ & $3(2)$ & 24 & \\
\hline Every day & $102(62)$ & 20.75 & \\
\hline Mobile phone for e & tertainmen & $(n=162)$ & \\
\hline Never used & $130(80)$ & 20.40 & 0.308 \\
\hline Used & $32(20)$ & 19.25 & \\
\hline Email $(n=163)$ & & & \\
\hline Never used & $149(91)$ & 20.38 & 0.072 \\
\hline Used & $14(9)$ & 17.50 & \\
\hline Facebook $(n=163)$ & & & \\
\hline Never used & $142(87)$ & 20.06 & 0.705 \\
\hline Used & $21(13)$ & 20.57 & \\
\hline Youtube $(n=163)$ & & & \\
\hline Never used & $150(92)$ & 20.19 & 0.662 \\
\hline Used & $13(8)$ & 19.46 & \\
\hline WhatsApp $(n=163)$ & & & \\
\hline Never used & $126(77)$ & 20.24 & 0.654 \\
\hline Used & 37 (23) & 19.76 & \\
\hline
\end{tabular}

Studies conducted with Type 2 diabetes patients in health-care settings in India indicate widespread lack of knowledge about diabetes. In a study in Mumbai, 9 in 10 respondents (87\%) did not know the 
Table 2: Health indicators with the mean knowledge score $(n=167)$

\begin{tabular}{|c|c|c|c|}
\hline Indicators & n (\%) & Mean knowledge score & p value \\
\hline \multicolumn{4}{|c|}{ Number of years since diabetes diagnosis $(N=167)($ median=13; mean=14.66; SD=9.58; Min=1; Max=57) } \\
\hline$\leq 10$ & $63(38)$ & 20.10 & \multirow[t]{2}{*}{0.856} \\
\hline$>10$ & $104(62)$ & 19.92 & \\
\hline \multicolumn{4}{|c|}{ Body mass index (BMI) $(n=163)($ median=26.48; mean=27.14; $S D=5.35 ; \operatorname{Min}=19.05 ; M a x=48.67)$} \\
\hline $18.5-22 \mathrm{~kg} / \mathrm{mg}^{2}$ & $33(20)$ & 20.53 & \multirow[t]{3}{*}{0.480} \\
\hline $23-24.9 \mathrm{~kg} / \mathrm{mg}^{2}$ & $32(20)$ & 20.76 & \\
\hline$\geq 25 \mathrm{~kg} / \mathrm{mg}^{2}$ & $98(60)$ & 19.50 & \\
\hline Yes & $7(4)$ & 20.71 & \multirow[t]{2}{*}{0.745} \\
\hline No & $159(96)$ & 19.97 & \\
\hline \multicolumn{4}{|c|}{ Low blood sugar reaction with symptoms such as sweating, weakness, anxiety, trembling, hunger, or headache in the past month ( $\mathrm{n}=159$ ) } \\
\hline Never & $112(70)$ & 19.39 & \multirow{2}{*}{0.056} \\
\hline 1 or more times & $47(30)$ & 21.38 & \\
\hline \multicolumn{4}{|c|}{$\begin{array}{l}\text { Number of days in the past month with high blood sugar with symptoms such as thirst, dry mouth and skin, increased sugar in the urine, less } \\
\text { appetite, nausea, or fatigue }(n=167)\end{array}$} \\
\hline Never & $113(68)$ & 19.91 & 0.809 \\
\hline Never & $141(91)$ & 20.09 & \multirow[t]{2}{*}{0.496} \\
\hline 1 or more times & $14(9)$ & 18.93 & \\
\hline \multicolumn{4}{|c|}{ Number of hospitalizations in the past year because of excessive blood sugar or hyperglycemia $(n=164)$} \\
\hline Never & $149(91)$ & 20.13 & 0.389 \\
\hline 1or more times & $15(9)$ & 18.73 & \\
\hline Hospitalization score & & & \\
\hline Never & $141(85)$ & 20.04 & 0.023 \\
\hline 1 time & $23(13)$ & 20.87 & \\
\hline 2 times & $3(2)$ & 11 & \\
\hline Comorbidities score $\mathrm{m}$ & dian=1; mea & $=0.84 ; \mathrm{SD}=0.621 ; \mathrm{Min}=0 ; \mathrm{Max}=2$ & 0.578 \\
\hline High blood pressure & & & \\
\hline Yes & $119(71)$ & 19.85 & 0.632 \\
\hline No & $48(29)$ & 20.33 & \\
\hline High cholesterol & & & \\
\hline Yes & $22(13)$ & 19.55 & 0.510 \\
\hline No & $145(87)$ & 20.06 & \\
\hline Yes & $51(30)$ & 19 & 0.152 \\
\hline No & $116(69)$ & 20.42 & \\
\hline Peripheral neuropathy & & & \\
\hline Yes & $32(19)$ & 18.72 & 0.176 \\
\hline No & $135(81)$ & 20.29 & \\
\hline Autonomic neuropathy & & & \\
\hline Yes & $28(17)$ & 19.04 & 0.350 \\
\hline No & $139(83)$ & 20.18 & \\
\hline Retinopathy & & & \\
\hline Yes & $9(5)$ & 20.56 & 0.768 \\
\hline No & $158(95)$ & 19.96 & \\
\hline Kidney disease & & & \\
\hline Yes & $13(8)$ & 20 & 0.994 \\
\hline No & $154(92)$ & 19.99 & \\
\hline Type of doctor to take & re of diabet & $s(n=165)$ & \\
\hline General practitioner & $39(24)$ & 18.13 & 0.025 \\
\hline M.D or specialist & $126(76)$ & 20.55 & \\
\hline Number of visits to doc & or for diabe & es in a year (median $=3$; Mean $=4.3$ & \\
\hline $1-3$ times & $91(57)$ & 20.96 & 0.036 \\
\hline$>3$ times & $69(43)$ & 18.97 & \\
\hline Tested blood sugar leve & $s$ in the pas & 4 weeks $(n=153)$ & \\
\hline Yes & $92(60)$ & 20.60 & 0.080 \\
\hline No & $61(40)$ & 18.85 & \\
\hline Number of times diabe & es has kept & spondent from doing normal dail & \\
\hline Never & $102(61)$ & 21.19 & 0.001 \\
\hline Sometimes & $65(39)$ & 18.11 & \\
\hline Having diabetes makes & ife difficult & & \\
\hline Disagree & $107(64)$ & 20.78 & 0.021 \\
\hline Agree or unsure & $60(36)$ & 18.58 & \\
\hline Received formal diabet & s education & & \\
\hline Yes & $7(4)$ & 21.14 & 0.605 \\
\hline No & $158(96)$ & 19.96 & \\
\hline
\end{tabular}

causes of diabetes, more than half were unaware of complications, and $37 \%$ did not know about the symptoms [22]. A study in the city of
Hyderabad reported the lowest mean knowledge score of $28 \%$ across various Indian studies [23]. Only a third of all the interviewed patients 
Table 3: Diabetes-related knowledge of respondents ( $n=167)$

\begin{tabular}{|c|c|c|c|}
\hline No & Characteristics & Category & N (\%) \\
\hline 1 & Diabetes can be cured & About the disease & $100(59.9)$ \\
\hline 2 & A fasting blood sugar level of 210 is too high & About the disease & $143(85.6)$ \\
\hline 3 & Kidneys produce insulin & About the disease & $70(41.9)$ \\
\hline 4 & $\begin{array}{l}\text { There are two main types of diabetes: Type } 1 \text { (insulin dependent) and Type } 2 \\
\text { (non-insulin dependent) }\end{array}$ & About the disease & 65 (38.9) \\
\hline 5 & An "insulin reaction" is caused by too much food & About the disease & $79(47.3)$ \\
\hline 6 & Shaking and sweating are signs of high blood sugar & About the disease & $148(88.6)$ \\
\hline 7 & Frequent urination and thirst are signs of low blood sugar & About the disease & $148(88.6)$ \\
\hline 8 & Infection is likely to cause an increase in blood sugar levels & About the disease & $86(51.5)$ \\
\hline 9 & Eating too much sugar and other sweet foods is a cause of diabetes & Causes & $94(56.3)$ \\
\hline 10 & The usual cause of diabetes is the lack of effective insulin in the body & Causes & $89(53.3)$ \\
\hline 11 & Diabetes is caused by the failure of kidneys to keep sugar out of urine & Causes & $78(46.7)$ \\
\hline 12 & In untreated diabetes, the amount of sugar in blood usually increases & Consequences/complications & $157(94.0)$ \\
\hline 13 & If I am diabetic, my children will have a higher chance of being diabetic & Consequences/complications & $116(69.5)$ \\
\hline 14 & Diabetes often causes poor circulation & Consequences/complications & $143(85.6)$ \\
\hline 15 & Cuts and abrasions on diabetes heal more slowly & Consequences/complications & $138(82.6)$ \\
\hline 16 & Diabetes can damage my kidney & Consequences/complications & $135(80.8)$ \\
\hline 17 & Diabetes can cause loss of feeling in my hands, fingers, and feet & Consequences/complications & $132(79.0)$ \\
\hline 18 & The best way to check my diabetes is by testing my urine & Management & $114(68.3)$ \\
\hline 19 & Medication is more important than diet and exercise to control my diabetes & Management & $30(18.0)$ \\
\hline 20 & Diabetics should take extra care when cutting their toenails & Management & $91(54.5)$ \\
\hline 21 & A person with diabetes should cleanse a cut with iodine and alcohol & Management & $99(59.3)$ \\
\hline 22 & Tight elastic hose or socks are not bad for diabetes & Management & $86(51.5)$ \\
\hline 23 & HbA1c is a test that measures your average blood glucose level in the past week & Management & $78(46.7)$ \\
\hline 24 & A can of diet soft drink can be used for treating low blood glucose levels & Management & $107(64.1)$ \\
\hline 25 & If you are beginning to have a low blood glucose reaction, you should lie down & Management & $63(37.7)$ \\
\hline 26 & Wearing shoes, a size bigger than usual, help prevent foot ulcers & Management & $16(9.6)$ \\
\hline 27 & When you are sick with the flu, you should test for glucose more often & Management & $70(41.9)$ \\
\hline 28 & $\begin{array}{l}\text { Having regular checkups with your doctor can help spot the early signs of diabetes } \\
\text { complications }\end{array}$ & Management & $132(79.0)$ \\
\hline 29 & Regular exercise will increase the need for insulin or other diabetic medications & Lifestyle (diet and activity) & $117(70.1)$ \\
\hline 30 & The way I prepare my food is as important as the food I eat & Lifestyle (diet and activity) & $145(86.8)$ \\
\hline 31 & A diabetic diet consists mainly of special foods & Lifestyle (diet and activity) & $137(82.0)$ \\
\hline 32 & For a person in good control, exercising has no effect on blood sugar levels & Lifestyle (diet and activity) & $132(79.0)$ \\
\hline \multicolumn{4}{|c|}{ Total knowledge score: Median=20; $M e a n=19.98 ; \mathrm{SD}=5.89 ; \mathrm{Min}=0 ; \mathrm{Max}=30$} \\
\hline
\end{tabular}

SD: Standard deviation, HbA1c: Glycosylated hemoglobin. Provides the number (\%) of respondents who answered each knowledge item/statement correctly

Table 4: Summary of multiple regression analysis

\begin{tabular}{|c|c|c|c|c|c|}
\hline No & Factor & B (unstandardized coefficient) & $\begin{array}{l}\text { Standard error of } \\
\text { unstandardized } \\
\text { coefficient beta }\end{array}$ & B (standardized coefficient) & p value \\
\hline 1 & Marital status & 4.063 & 1.193 & 0.261 & 0.001 \\
\hline 2 & Number of children & -2.342 & 1.012 & -0.188 & 0.022 \\
\hline 3 & $\begin{array}{l}\text { Graduate or postgraduate level } \\
\text { education }\end{array}$ & 1.683 & 0.676 & 0.205 & 0.014 \\
\hline 4 & Type of doctor & 1.896 & 1.107 & 0.131 & 0.089 \\
\hline 5 & Number of annual visits to doctor & -2.058 & 0.955 & -0.170 & 0.033 \\
\hline 6 & $\begin{array}{l}\text { Number of diabetes-related } \\
\text { hospitalization episodes }\end{array}$ & 0.687 & 1.153 & 0.047 & 0.552 \\
\hline 7 & $\begin{array}{l}\text { Diabetes affects my normal } \\
\text { activities in life }\end{array}$ & -2.335 & 1.212 & -0.183 & 0.056 \\
\hline 8 & Diabetes makes my life difficult & 0.046 & 1.217 & 0.004 & 0.970 \\
\hline
\end{tabular}

in a study in rural Maharashtra state had correct knowledge about diabetes [33]; while in rural Gujarat, neighboring state interviews with female patients found a knowledge score of $42 \%$ [21]. Similarly, two studies from southern India $[34,35]$ reported that less than half of the patients had correct knowledge; however, a study in the state of Kerala reported a knowledge score of $62 \%$ [36].

This study used an adapted version of a validated standardized diabetes knowledge test questionnaire from the Starr County Diabetes Education Study [28]. Globally, studies that used this instrument reported similar or lower knowledge scores: 46\% in Nepal [37], 53\% in Peru [38], and $59 \%$ in Pakistan [39] to 60\% in Malta [40]. Similarly, studies that used other knowledge testing instruments with Type 2 diabetes patients reported scores ranging between $39 \%$ in a Nigerian sample [41] to $68 \%$ in Turkey [42]; with patients in Zimbabwe, UAE, Singapore, and Iran scoring between $43 \%$ and $61 \%$ [29,43-45].

Our finding that higher levels of education were associated with greater knowledge of diabetes is supported by several other studies [42,43,46-49]. Higher education has been found to be an independent determinant of the total knowledge as well as insulin use knowledge scores [43]. People who are more educated probably understand information about the disease better, ask questions, and may use information to self-manage the disease. Studies have shown that less educated patients often have difficulty in understanding physicians' explanations about diabetes and its management $[50,51]$. 
This study also found that participants who were not married, had two or less children, and visited the doctor for diabetes care between 1 and 3 times a year had higher knowledge scores. To understand these findings, we conducted further analysis of the dataset and found that that those with higher levels of education (graduate and postgraduate) were significantly $\left({ }^{*} \mathrm{p}<0.05\right)$ more likely to have two or less children, use the internet, consult a specialist as against a general practitioner, and get a blood sugar test done in the preceding 4 weeks.

This study clearly points out that there are information gaps among patients, even in an urban hospital setting and that difference in education levels seems to be spilling over and generating inequity in information about diabetes. Further, research must explore the link between education level and diabetes knowledge, and assess if these disparities are a direct result of education itself or mediated through income and access to resources. For instance, those with higher education may simply comprehend better the information provided by a doctor. However, it is also possible that higher education is related to better employment and income which, in turn, translates to access to quality or specialized health care (better doctors) and related networks and thus improves knowledge and management [50]. Those with lesser education have been found to lack resources and access due to socioeconomic barriers and also have lower self-efficacy which leads to poor processing of information rather than the education level itself leading directly to an information deficit [52]. A nuanced understanding of how patients receive, perceive, and process information will help craft effective DSME programs in the Indian urban context, especially targeting those with limited resources and access, thereby leading to improved management and prevention of complications.

\section{LIMITATIONS}

The cross-sectional study design implies weakness in the determination of causal relationships. The survey method relied on self-reports which could have led to biased responses. Furthermore, participants were recruited from among those admitted in a private hospital whose socioeconomic situation may not be comparable to patients attending public hospitals, limiting the generalizability of the results. Future research in health-care facilities serving patients from diverse social strata will help determine the true levels of disease knowledge among all diabetes patients.

\section{CONCLUSION}

This study highlights the need to better understand and address the information disparities in Type 2 diabetes patients. Public and private health-care facilities could integrate diabetes education interventions through a combination of provider-led and innovative information communication technology methods into waiting rooms, outpatient departments, and inpatient wards. Facilities can also ensure that medical consultations are embedded with messages or materials on diabetes, making information accessible for Type 2 diabetic patients regardless of their socioeconomic status. Such interventions have resulted in sustained improvement in disease knowledge and care [53]. Facility-based education activities can be supplemented with mobile phone-based and social media applications (WhatsApp), along with bursts of traditional mass media communication, especially through television, for wider reach. DMSE interventions are urgently required in India, and they have to span the facility to home continuum, but this will need political will of health-care decision makers, and capacity building and sensitization of providers. Such interventions must shift the needle of diabetes management from a doctor-centric approach to a patient and family-centric one, helping patients to develop appropriate competencies and attitudes to manage their condition and become selfreliant.

\section{ACKNOWLEDGMENTS}

We would like to acknowledge the efforts of Dr. Ritika Dante and Vidya in the data collection process; Aishwarya Bhattacharya for data entry and Shirlly Koshy for data management. We also thank the management of Dr. L.H. Hiranandani Hospital, Powai, for permission to conduct the study and the doctors and nurses for their support in the data collection process in the inpatient wards. Most importantly, we are grateful to the patients who freely gave their time and inputs.

\section{AUTHORS' CONTRIBUTIONS}

VP and NC conceptualized the study. VP collected the data. GF and NC analyzed the data. GF, NC, and VP drafted and revised the manuscript.

\section{CONFLICTS OF INTEREST}

The authors declare that they have no conflicts of interest.

\section{REFERENCES}

1. International Diabetes Federation (IDF). IDF Atlas. $8^{\text {th }}$ ed. Brussels: IDF; 2017

2. Wild S, Roglic G, Green A, Sicree R, King H. Global prevalence of diabetes: Estimates for the year 2000 and projections for 2030. Diabetes Care 2004;27:1047-53

3. Indian Council of Medical Research (ICMR). Public Health Foundation of India (PHFI), and Institute for Health Metrics and Evaluation (IHME). India: Health of the Nation's States - The India State Level Disease Burden Initiative. New Delhi: ICMR, PHFI, IHME; 2017.

4. Anjana RM, Deepa M, Pradeepa R, Mahanta J, Narain K, Das HK, et al. Prevalence of diabetes and prediabetes in 15 states of India: Results from the ICMR-INDIAB population-based cross-sectional study. Lancet Diabetes Endocrinol 2017;5:585-96.

5. World Health Organization. Global Report on Diabetes. Geneva: World Health Organization; 2016.

6. Bommer C, Sagalova V, Heeseman E, Manne-Goehler J, Atun R, Bärnighausen T, et al. Global economic burden of diabetes in adults: Projections from 2015 to 2030. Diabetes Care 2018;41:963-70.

7. Seuring T, Archangelidi O, Suhrcke M. The economic costs of Type 2 diabetes: A global systematic review. Pharmacoeconomics 2015;33:811-31.

8. Dey S. Yearly Spend on diabetes is Rs 1.5 lakh cr, rising by $30 \%$ pa. The Times of India. 2016. Available from: http://www.epaperbeta. timesofindia.com/Article. aspx?eid=31808\&articlexml=Yearlyspend-on-diabetes-is-Rs-15-lakh-09022016018024. [Last cited on 2018 Jun 05].

9. Ramachandran A, Ramachandran S, Snehalata C, Augustine C, Murugesan N, Viswanathan V, et al. Increasing expenditure on health care incurred by diabetic subjects in a developing country: A study from India. Diabetes Care 2007;30:252-6.

10. Kapur A. Economic analysis of diabetes care. Indian J Med Res 2007;125:473-82.

11. Wilkinson A, Whitehead L, Ritchie L. Factors influencing the ability to self-manage diabetes for adults living with Type 1 or 2 diabetes. Int J Nurs Stud 2014;51:111-22.

12. Nam S, Chesla C, Stotts NA, Kroon L, Janson SL. Barriers to diabetes management: Patient and provider factors. Diabetes Res Clin Pract 2011;93:1-9.

13. Pace AE, Ochoa-Vigo K, Caliri MH, Fernandes AP. Knowledge on diabetes mellitus in the self-care process. Rev Lat Am Enfermagem 2006;14:728-34.

14. Berikai P, Meyer P, Kazlauskaite R, Savoy B, Kozik K, Fogelfeld L. Gain in Patients' knowledge of diabetes management targets is associated with better glycemic control. Diabetes Care 2007;30:1587-9.

15. Funnell M, Tang T, Anderson R. From DSME to DSMS: Developing empowerment-based diabetes self-management support. Diabetes Spectr 2007;20:221-6.

16. Kent D, Melkus GD, Stuart PM, McKoy JM, Urbanski P, Boren SA, et al. Reducing the risks of diabetes complications through diabetes self-management education and support. Popul Health Manag 2013;16:74- 81 .

17. Strine TW, Okoro CA, Chapman DP, Beckles GL, Balluz L, Mokdad AH. The impact of formal diabetes education on the preventive health practices and behaviors of persons with Type 2 diabetes. Prev Med 2005;41:79-84.

18. Dussa KN, Sahay RK, Sundarajan P, Vishnuvardhanarao M. Adaptation of diabetes knowledge questionnaire for South Asian countries context. Int J Pharm Pharm Sci 2017;9:252-6.

19. Mohan D, Raj D, Shanthirani CS, Datta M, Unwin NC, Kapur A, 
et al. Awareness and knowledge of diabetes in Chennai--the Chennai Urban rural epidemiology study [CURES-9]. J Assoc Physicians India 2005;53:283-7.

20. Deepa M, Bhansali A, Anjana RM, Pradeepa R, Joshi SR, Joshi PP, et al. Knowledge and awareness of diabetes in urban and rural India: The Indian council of medical research India diabetes study (phase I): Indian council of medical research India diabetes 4. Indian J Endocrinol Metab 2014;18:379-85.

21. Mehta N, Trivedi M, Maldonado LE, Saxena D, Humphries DL. Diabetes knowledge and self-efficacy among rural women in Gujarat, India. Rural Remote Health 2016;16:3629.

22. Kazi N, Bote M, Raikar K. Knowledge, attitude and practices about diabetes mellitus and its complications in T2DM patients attending the UHC in Mumbai. Int J Community Med Public Health 2017;4:2793-7.

23. Dussa K, Parimalakrishnan S, Sahay R. Assessment of diabetes knowledge using diabetes knowledge questionnaire among people with Type 2 diabetes mellitus. Asian J Pharm Clin Res 2015;8:254-6.

24. Press Trust India. With Total Wealth Worth $\$ 950$ Billion, Mumbai is $12^{\text {th }}$ Richest City Globally. The Times of India. 2018. Available from: http://www.indianexpress.com/article/india/with-total-wealth-worth950-billion-mumbai-is-12th-richest-city-globally-5059348/. [Last cited on 2018 Jun 05].

25. Directorate of Census Operations, Maharashtra. Mumbai District Census Handbook. Mumbai: Government of India; 2011.

26. Municipal Corporation of Greater Mumbai (MCGM). Mumbai Human Development Report 2009. Mumbai: MCGM; 2010. Available from: http://www.indiaenvironmentportal.org.in/files/Mumbai\%20HDR $\% 20$ Complete.pdf. [Last cited on 2018 Jun 05]

27. Salve P. Mumbai has the Best Healthcare. It Isn't Enough. India Spend; 2014. Available from: http:/www.indiaspend.com/cover-story/ mumbai-has-indias-best-healthcare-it-isnt-enough-69529. [Last cited on 2018 Jun 06]

28. Garcia A, Villagomez ET, Brown SA, Kouzekanani K, Hanis CL. The Starr county diabetes education study development of the Spanish-language diabetes knowledge questionnaire. Diabetes Care 2001;24:16-21.

29. Hashim MJ, Mustafa H, Ali H. Knowledge of diabetes among patients in the United Arab Emirates and trends since 2001: A study using the Michigan diabetes knowledge test. East Mediterr Health J 2017;22:742-8

30. Dos Santos PF, dos Santos PR, Ferrari GS, Fonseca GA, Ferrari CK. Knowledge of diabetes mellitus: Does gender make a difference? Osong Public Health Res Perspect 2014;5:199-203.

31. Perera DP, De Silva RE, Perera WL. Knowledge of diabetes among Type 2 diabetes patients attending a primary health care clinic in Sri Lanka. East Mediterr Health J 2013;19:644-8

32. Rankin D, Heller S, Lawton J. Understanding information and education gaps among people with Type 1 diabetes: A qualitative investigation. Patient Educ Couns 2011;83:87-91

33. Khapre MP, Mude A, Goyal RC, Wagh V. Low awareness of diabetes affecting the clinical outcome of patient: A cross-sectional study conducted in rural tertiary care hospital. Int $\mathrm{J}$ Biol Med Res 2011;2:627-30

34. Deepali BS, Subramanian M, Soumya G, Nagashree N. Knowledge of diabetes, its complications and treatment adherence among diabetic patients. Int J Community Med Public Health 2017;4:2428-34.

35. Hussain R, Giridhar R, Gopalakrishnan M, Gopalakrishnan M, Sadasivan S, James J, et al. Knowledge and awareness about diabetes mellitus and diabetic retinopathy in suburban population of a South Indian state and its practice among the patients with diabetes mellitus: A population-based study. Indian J Ophthalmol 2016;64:272-6.

36. Kurian B, Qurieshi MA, Ganesh R, Kamalamma L. A communitybased study on knowledge of diabetes mellitus among adults in a rural population of Kerala. Int J Noncommun Diseases 2016;1:59-64.

37. Shrestha S, Thapa P, Saleh F, Thapa N, Stray BP, Khanom K. Knowledge of diabetes mellitus among pregnant women in three districts of Nepal. J Nepal Health Res Counc 2013;11:259-63.

38. Cantaro K, Jara J, Taobada M, Mayta-Tristan P. Association between information sources and level of knowledge about diabetes in patients with Type 2 diabetes. Endocrinol Nutr 2016;63:202-11.

39. Bukhsh A, Lee S, Pusparajah P, Khan AH, Khan TM. Psychometric properties of the Urdu version of diabetes knowledge questionnaire. Front Public Health 2017;5:139.

40. Formosa C, Muscat R. Improving diabetes knowledge and self-care practices. J Am Podiatr Med Assoc 2016;106:352-6.

41. Odili V, Isiboge P, Eregie A. Patients' knowledge of diabetes mellitus in a Nigerian city. Trop J Pharm Res 2011;10:637-42.

42. Gunay T, Ulusel B, Velipasaoglu S, Unal B, Ucku R, Ozgener N. Factors affecting adult knowledge of diabetes in Narlidere health district, Turkey. Acta Diabetol 2000;43:142-7.

43. Mufunda E, Ernerssson A, Hjelm K. Limited knowledge of diabetes in patients attending an outpatient diabetes clinic at a referral hospital in Zimbabwe: A cross-sectional study. Pan Afr Med J 2018;29:144

44. Zainudin SB, Ang DY, Soh AW. Knowledge of diabetes mellitus and safe practices during Ramadan fasting among Muslim patients with diabetes mellitus in Singapore. Singapore Med J 2017;58:246-52.

45. Niroomand M, Ghasemi SN, Karimi-Sari H, Kazempour-Ardebili S, Amiri P, Khosravi MH. Diabetes knowledge, attitude and practice (KAP) study among Iranian in-patients with Type-2 diabetes: A crosssectional study. Diabetes Metab. Syndr 2016;10:S114-9.

46. Long P, Long K, Kedia A, Gren LH, Smith A, Biswas J. A cross-sectional study of diabetic knowledge in West Bengal, India: An analysis based on access to health care. Int J Diabetes Dev Ctries 2015;35:614-9.

47. Fenwick E, Xie J, Rees G, Finger RP, Lamoureux EL. Factors associated with knowledge of diabetes in patients with Type 2 diabetes using the diabetes knowledge test validated with Rasch analysis. PLoS One 2013;8:e80593.

48. Yun LS, Hassan Y, Aziz NA, Awaisu A, Ghazali R. A comparison of knowledge of diabetes mellitus between patients with diabetes and healthy adults: A survey from north Malaysia. Patient Educ Couns 2007;69:47-54.

49. Thomas SM, Gajjar SN, Reddy UK, Devi H. A prospective study: Knowledge assessment and patient care of diabetic foot ulcer patients in tertiary care hospital. Int J Pharm Pharm Sci 2017;9:104-10.

50. Murata G, Shah J, Adam K, Wendel CS, Bokhari SU, Solvas PA, et al. Factors affecting diabetes knowledge in Type 2 diabetic veterans. Diabetologia 2003;46:1170-8.

51. Larme AC, Pugh JA. Evidence-based guidelines meet the real world: The case of diabetes care. Diabetes Care 2001;24:1728-33.

52. Walker RJ, Smalls BL, Egede LE. Social determinants of health in adults with Type 2 diabetes-contribution of mutable and immutable factors. Diabetes Res Clin Pract 2015;110:193-201.

53. Van Den Arend IJ, Stolk RP, Rutten GE, Schrijvers GP. Education integrated into structured general practice care for Type 2 diabetic patients results in sustained improvement of disease knowledge and self-care. Diabet Med 2000;17:190-7. 